\title{
ALTERAÇÕES PANCREÁTICAS EM BOVINOS NATURALMENTE INFECTADOS POR Eurytrema sp E SUA ASSOCIAÇÃO COM A CARGA PARASITÁRIA E O NÚMERO DE OVOS POR GRAMA DE FEZES (OPG)*
}

\author{
GRADATION OF MICROSCOPIC LESIONS IN PANCREAS OF EUrytrema sp NATURALLY INFECTED CATTLE AND \\ ITS RELATIONSHIP WITH THE PARASITE LOAD AND NUMBER OF EGGS PER GRAM OF FAECES (EPG)
}

\author{
Pacifico Antonio Diniz. BELÉM'; Mauro Rodrigues de OLIVEIRA²; Carlos Roberto PAD()VANI'; Maria Cecilia Rui LUVIZO'TTO'
}

\section{RESUMO}

Foram examinados, ao microscópio óptico, fragmentos de 41 pâncreas de bovinos naturalmente infectados por Eurytrema sp e as lesões encontradas foram classificadas em quatro graus. de acordo com sua extensão desde o epitélio dos ductos. Em seguida, tomando-se os valores das cargas parasitárias (CP) e o número de ovos por grama de fezes (OPG) dos animais, em cada grau de lesão estabelecido, comprovou-se que os valores do OPG e, principalmente, da CP podem ser utilizados para caracterizar, de maneira satisfatória, a extensão das lesões pancreáticas.

UNITHRMOS: Eurytrema: Lesões; Pâncreas; Parasitas

\section{INTRODUÇÃO}

Partindo-se da premissa de que, nos casos de infecção por Eurytrema sp, em bovinos, as lesõęs iniciam-se nos ductos e, progressivamente, estendem-se aos tecidos glandulares ${ }^{8.12,35}$, parece óbvio que as mais leves devam restringir-se ao epitélio dos ductos parasitados e aquelas mais graves tomem áreas consideráveis de lóbulos vizinhos ou, em casos extremos, até mesmo sejam difusas, configurando os verdadeiros quadros de fibrose descritos na literatura ${ }^{1.3 .4 .14 .21,22,24} \mathrm{e}$, inclusive, produzindo sintomatologia de insuficiência pancreática endócrina ${ }^{3,8,14,15,30}$. Evidentemente, no entanto, é de se esperar que diversas situações intermediárias de extensão das lesões possam ser surpreendidas.

Seguindo-se o raciocínio explicitado acima, procurou-se, inicialmente, graduar as alterações microscópicas verificadas no material obtido c, cm seguida, alocar as unidades experimentais em cada grau de lesão. Por fim, tomando-se a carga parasitária (CP) e o número de ovos por grama de fezes (OPG), passou-se a avaliar se eles poderiam ser usados como parâmetros para indicar os graus de lesão correspondentes.

\section{MATERIAL E MÉTODO}

Foram utilizados pâncreas e respectivas amostras fecais de 39 bovinos, machos ou fêmeas, pertencentes a diferentes raças e oriundos de diferentes propriedades rurais, que foram abatidos em São Manoel, Estado de São Paulo, entre 23/1 1/ 87 e 25/01/88, além de outros dois necropsiados na Faculdade de Medicina Veterinária c Zootecnia da UNESP/Botucatu (FMVZ). Todos os animais eram adultos, criados $\mathrm{cm}$ regime de pasto e procedentes de municípios da mesorregião do Sudoeste Paulista.

Após evisceração dos animais, os pâncreas parasitados e uma amostra mínima de $10 \mathrm{~g}$ de fezes, contida na ampola retal, eram recolhidos, acondicionados em sacos plásticos individuais previamente identificados e, por fim, transportados para a FMVZ, onde todo esse material era processado.

As amostras de fezes eram mantidas $\mathrm{cm}$ geladeira, até o momento de serem submetidas a exame parasitológico segundo técnica descrita por BELEM et al. ${ }^{2}$ (1992). Os pâncreas eram colocados em bandejas individuais, isolados, lavados e toda água usada era passada através de peneiras de nylon para separação dos trematódeos desgarrados. A seguir, os canais pancreáticos eram abertos com o auxílio de uma tesoura e os helmintos retirados e contados. Durante esta etapa colhiam-se diversos fragmentos para exame histológico, respeitando-se a condição de retirá-los de locais onde haviam ductos parasitados. Os vários fragmentos colhidos de cada órgão eram, em conjunto, envolvidos por gaze e colocados em frascos contendo formol a $10 \%$ para fixação. Posterior-

1-Professor Adjunto-Universidade Federal de Viçosa

2-Professor Adjunto-Faculdade de Medicina Veterinária e 7ootecnia da UNESP-Campus de Bolucatu

3-Professor Adjunto-Instituto de Biociéncias da UNESP-Campus de Botucatu

4-Professor Assistente-Faculdade de Medicina Veterinária e Zootecnia da UNESP-Campus de Botucatu

"Pane da rese "Aspectos ligados ao diagnóstico da infecção por Eurytrema sp em bovinos" 
BFI.IM. P.A.D.; OI.IVI:IRA. M.R.; PADOVANI.C.R.; L.UVIZOTTO, M.C.R. Alteraçìes pancréticas em bovinos natural mente infectados por Eurytrema sp e sua assuxiação com a carga parasitária e o número de ovos por grama de fezes (OPC). Rraz. J. vet. Res. anim. Sci.. Săo Paulo, v. 31, n. 3/4, p. 273-81, 1994

mente, ao acaso, quatro fragmentos de cada órgão eram processados pela técnica rotineira de inclusão em parafina, cortados a 5 micrômetros de espessura, corados pela hematoxilina e cosina e examinados ao microscópio óptico. A partir daí, de posse das características morfologicas das lesōes constatadas nos cortes histológicos dos fragmentos de cada pâncreas, procurou-se estabelecer critérios que permitissem graduá-las de acordo com a extensão das alterações verificadas. Finalmente, por meio da análise de variância para experimentos inteiramente casualizados, complementada com o teste de comparações múltiplas de Tukey, verificou-se se os graus de lesão observados diferiam estatisticamente, tomando-se como parâmetros a carga parasitária (CP) e o OPG transformados, respectivamente, para (CP) ${ }^{1 / 2} \mathrm{e}(\mathrm{OPG}+$ $0,5)^{1 / 2}$. A estimação dos valores médios do OPG e CP, nos diferentes graus de lesão, foi obtida pela construção dos intervalos de confiança para as médias populacionais, ao nível de $95 \%$ de confiabilidade ${ }^{25}$.

\section{RESULTADOS E DISCUSSÃO}

O exame histológico dos fragmentos de pâncreas permitiu caracterizar as lesões existentes com base na sua localização preferencial e a predominância dos tipos de alterações verificadas. Isto feito, foi possível definir os quatro graus de lesão seguintes:

-GRAU I: pâncreas normais ou, então, com lesčres incipientes e geralmente restritas ao epitélio dos ductos em, no máximo, metade dos cortes histológicos examinados. Neste caso, podia-se observar dilatação da luz devido à presença de parasitas ou infiltração de poucas células inflamatórias nas paredes de alguns ductos interlobulares. Às vezes observavase, também, achatamento do epitélio e, ou, hiperplasia cpitelial leve, porém nunca alteração na espessura das paredes dos ductos e tampouco fibroplasias (Fig. 1).

-GRAU II: pâncreas com espessamento moderado das paredes dos ductos, devido à fibroplasia, em mais de $50 \%$ das lâminas examinadas, bem como lesōes descritas para o Grau I em caráter mais acentuado. Alguns ductos mostraram ainda sinais de fibroplasia leve das paredes, mas sem tendência à invasão do parênquima adjacente e diminuição da luz (Fig. 2).

-GRAU III: pâncreas que, em pelo menos metade das lâminas examinadas, apresentaram lesões confinadas às paredes de todos os ductos, especialmente os de maior diâmetro. Constatou-se, sobretudo, espessamento nítido das paredes dos ductos interlobulares devido à fibroplasia e reação inflamatória que, não raro, produziam estenose. Observou-se, ainda, hiperplasia moderada de ductos em algumas lâminas e dilatação de uns poucos ductos interlobulares parasitados, estes apresentando também as alterações parietais ja salientadas (Fig. 3).

-GRAU IV: a rigor, o tipo de lesão aqui descrito corresponde ao anterior, porém associado à marcante proliferação conjuntiva no parênquima adjacente aos ductos e, por vezes. situações $\mathrm{cm}$ que uma ou mais lâminas examinadas apresentaram tendência à difusão das lesões a todo o fragmento ou parte ampla dele. Pode-se observar atrofia severa de ácinos glandulares e. ou, substituição de outros por tecido conjuntivo, notadamente nas regiōes periductais. Ademais, ocorreram alguns casos de oclusão total ou parcial de ductos e, cm um único animal, células gigantes e raros ovos do parasita nas paredes de um ducto semi-ocluído. Há de se registrar, ainda, que aqui também as lesões foram observadas em, pelo menos, metade dos cortes histológicos dos fragmentos de pâncreas de cada animal (Fig. 4).

A despeito de vários autores terem demonstrado alterações microscópicas similares às aqui encontradas $1.5,6,7,8.10,11,12,16,17,19,21,22,23.24,27,28,29.33 .35$, somente em uma lâmina foram observados ovos de Eurytrema sp (raros) na parede de um ducto pancreático, onde se apresentavam circundadas pelas clássicas lesões a eles associadas $1,3,4,5,6,10.11,16,18,19.23,24,27,28,29.33$. Por outro lado, não ocorreram casos de redução do número de ilhotas de Langerhans ou rarefação do seu conjunto celular, a exemplo do que comprovaram FIGUEIREDO"l (1928), BURGGRAAF ${ }^{8}$ (1935), TORRES; PINTO ${ }^{33}$ (1936); CORREA et al. ${ }^{10}$ (1984), JUBB et al. ${ }^{17}$ (1985) e OLIVEIRA; BECHARA ${ }^{24}$ (1988), e muita fibrose, tal como observaram NIEBERLE; COHRS 21 (1970); KONO et al. ${ }^{19}$ (1980); HARADA et al. ${ }^{14}$ (1980) e JONES; HUNT ${ }^{16}$ (1983). Provavelmente estes fatos indiquem uma menor gravidade das lesões estudadas pois: $1^{\circ} \mathrm{O}$ achado de ovos no tecido glandular e lesões associadas é interpretado por NOSADA et al. ${ }^{23}$ (1970) como indício de maior gravidade da injúria produzida pelos helmintos; $2^{\circ}$ as ilhotas de Langerhans somente apresentam alterações $\mathrm{cm}$ casos mais avançados, quando a fibrose é mais inten$\mathrm{sa}^{8,11,12,17,33} ; 3^{\circ}$ a cirrose pancreática é, indiscutivelmente, um evento terminal na euritrematose bovina e ela não foi aqui verificada em nenhum caso. É possível que a ausência dessas alterações possa ser atribuída principalmente a diferenças a menor nas cargas parasitárias, porquanto valores bem mais elevados que os ora relatados têm sido descri$\operatorname{tos}^{1,9,26}$ e autores que observaram graus de infecção aparentemente similares àqueles aqui verificados ${ }^{7.32}$ deixaram de reportá-las. No entanto, há de se ter em mente que, se se tivesse efetuado este mesmo tipo de estudo em animais que apresentassem maior intensidade de parasitismo, novos graus de lesão, provavelmente mais graves, seriam caracterizados, já que outras alterações aqui não verificadas fatalmente o seriam. De fato, FIGUEIREDO ${ }^{11}$ (1928) já admitira que a 
BELEM, P.A.D.: OLIVEIRA. M.R.: PADOVANI,C.R.; LUVIZOTIO, M.C.R. Alteraçōes pancré́ticas em bovinos naturalmente infectados por Eurytrema șp e sua associą̧ăı com a carga parasitária e o número de ovos por grama de fezes (OPG). Braz. J. vet. Res. anim. Sci., Sāo Paulo, v.31, n.3/4, p. 273.81, 1994.

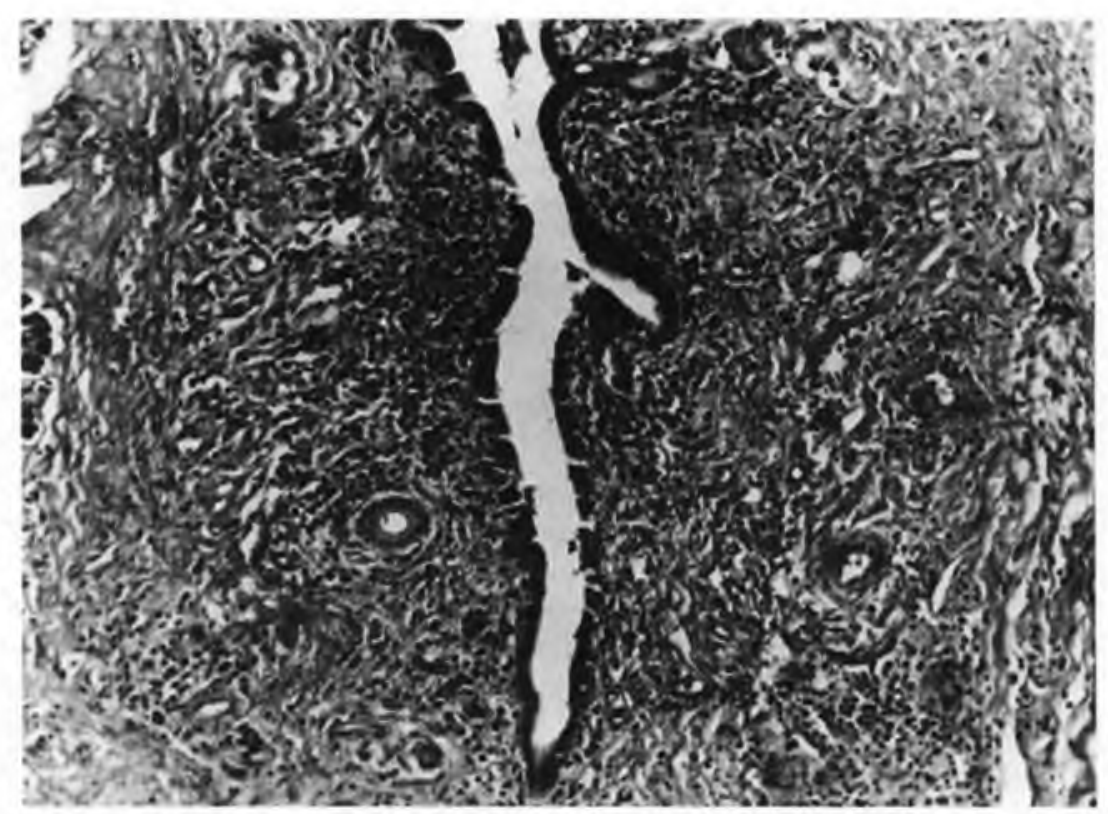

FIGURA 1

A figura mostra a parede de um ducto exibindo leve infiltrado inflamatório constituído de células mononucleares, que foi a única lesão verificada neste e nos demais fragmentos de pâncreas examinados deste animal - caso enquadrado como o Grau I. H.E. $(100 \mathrm{x})$.

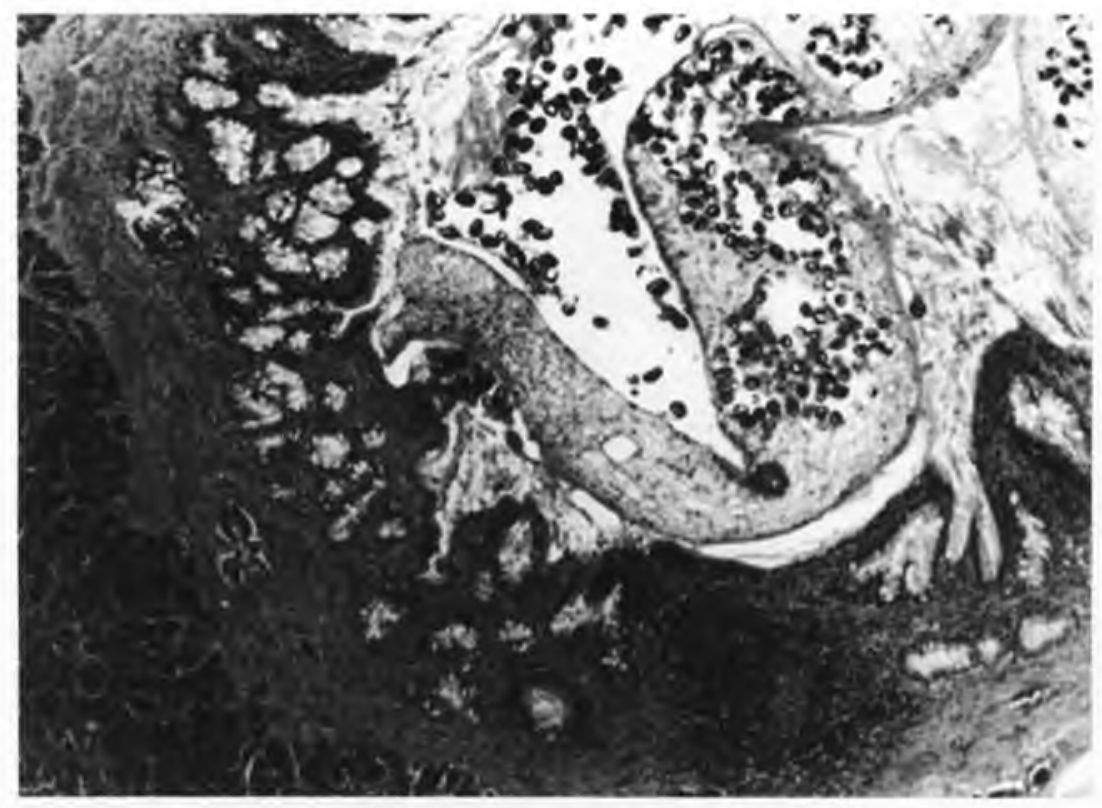

FIGURA 2

Lesão classificada como do Grau II. Nesta tigura nota-se hiperplasia epitelial nítida e espessamento moderado das paredes de um ducto, onde se vê, também, evidente infïltrado inflamatório constituído de células mononucleares. O ducto acha-se muito dilatado e, em seu interior, aparece um espécime de Eurytrema sp e ovos deste parasita. As lesões, contudo, restringem-se às paredes do ducto. H.E. $(32 \mathrm{x})$. 
BLLÉM, P.A.D.: OLIVEIRA. M.R.; PADOVANI, C.R.; LUVIZOTTO. M.C.R. Alteraçð̌es pancreáticas em bovinos naturalmente infectados por Eurytrema spe sua assuxiaçăo com a carga parasitária e o número de ovos por grama de fezes (OPG). Braz. J. vet. Res. anim. Sci.. Sžo Paulo. v. 31. n. 3/4. p. 273-81. 1994.

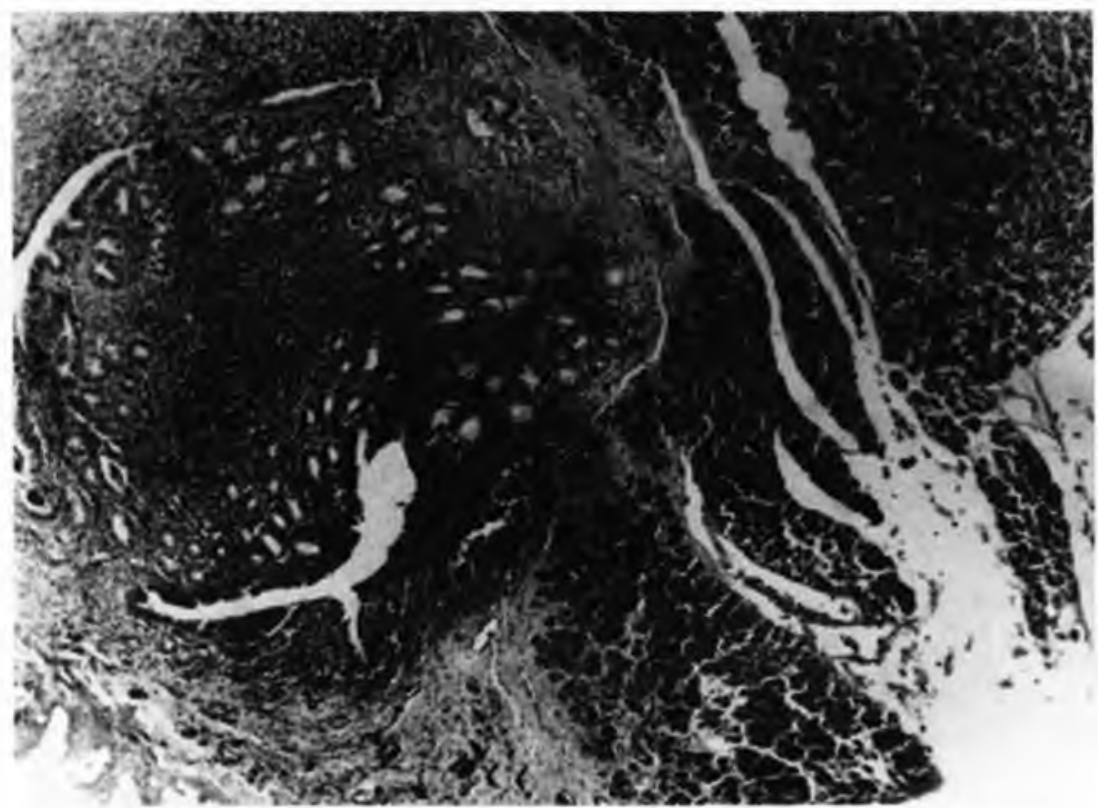

FIGURA 3

Aspecto predominante das lesões classificadas como do Grau III: espessamento nítido das paredes de um ducto pancreático de maior calibre, o qual exibe ainda intenso infiltrado inflamatório constituído de células mononucleares. Vê-se também hiperplasia epitelial e estenose do ducto, além de leve tendência à proliferação conjuntiva no parênquima periductal. H.E. $(32 \mathrm{x})$.

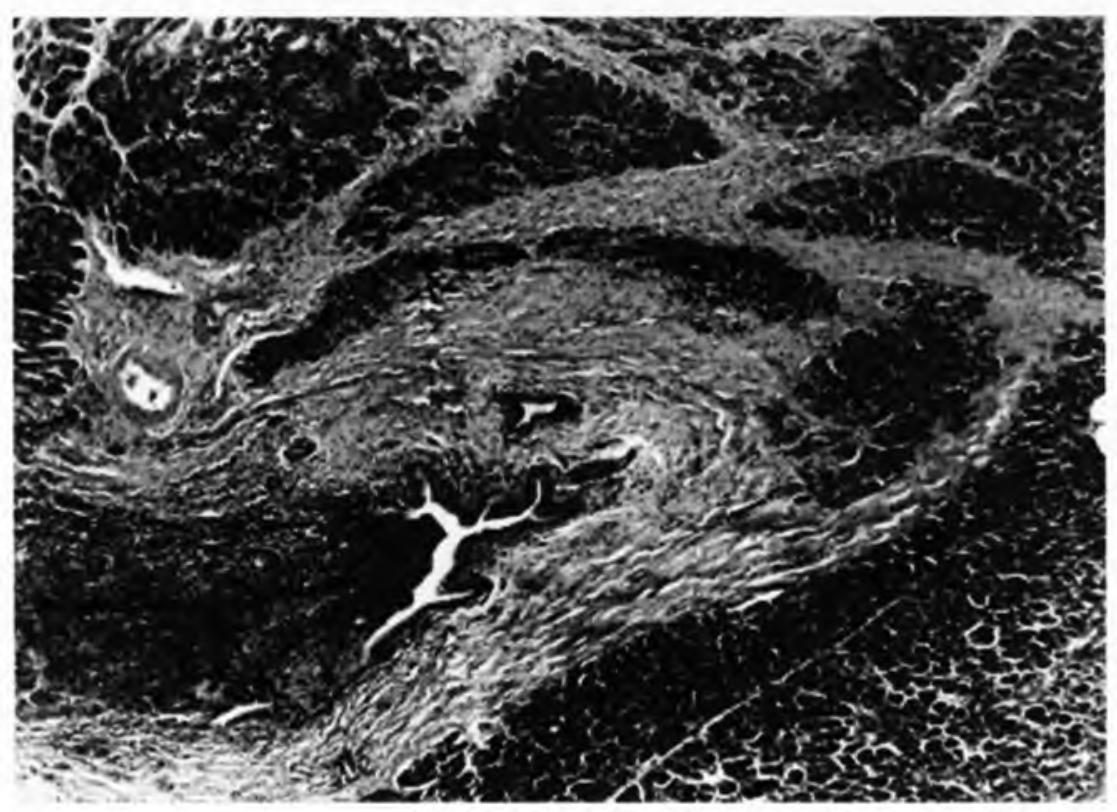

FIGURA 4

Lesão do Grau IV, chamando a atenção a marcante proliferação conjuntiva no parênquima adjacente ao ducto pancreático, a qual confere à lesão uma característica difusa em extensa área do fragmento examinado. Vê-se, ainda, intensa reação inflamatória e alguns ovos de Eurytrema sp incrustados na parede de um ducto. H.E. (32 x). 
BFLLF.M, P.A.D.: OL.IVEIRA, M.R..PAIXJVANI. C.R.: LUVIZOTTO. M.C.R. Alteraçōes patncreáticas em bovinos naturalmente infectados por Eurytrema sp e sua associaçăo com a carga parasitária e o número de ovos por grama de fezes (OPG). Braz.. J. vet. Res. anim. Sci., São Paulo, v.31, n. 3/4. p. $273-81$, 1994.

extensão das lesões pancreáticas de bovinos, nos casos de parasitismo por Eurytrema sp, depende do grau de infecção e trabalhos posteriores, ainda que implicitamente sugeriram a mesma associação $1,8,10,16,21,32,33$.

Definidos morfologicamente os quatro graus de lesão e encerrada a alocação das unidades experimentais em cada um deles (Tab. 1), passou-sc a avaliar se o número de parasitas poderia ser usado como parâmetro para indicá-los, pois, conforme já se referiu, há fortes evidências de relação entre esta variável e grau de lesão. De fato, tal como se vê na Tab. 2, apenas os graus l e II não puderam ser diferenciados entre si, com base na raiz quadrada do número médio de parasitas. Todavia, verifica-se que o número de parasitas $\mathrm{em}$ cada tratamento sofreu variação relativa muito grande e, provavelmente por causa disto, não foi possível assinalar diferença estatisticamente significativa entre os graus I c II quanto ao número médio de parasitas responsável por eles. É possível que, além da clássica interferência de fatores como prenhez, estado nutricional, idade do animal e outros ${ }^{34}$, a variação citada possa ser atribuída também ao tempo durante o qual cada hospedeiro esteve sob ação daquele número de parasitas (c mesmo outros anteriores) já que os casos estudados são de infecção natural e, como tais, estão sujeitos a reinfestaçĩes. Adicionalmente, deve-se considerar ainda que a variação anatômica do pâncreas ${ }^{4,13}$ deve afetar diretamente a proporção do número de parasitas por unidade de área e, por conseguinte, a intensidade das lesões produzidas por um mesmo número de parasitas. Na Tab. 3 são apresentados os intervalos de confiança para o número médio de parasitas relativo a cada grau de lesão pancreática de bovinos pertencentes a um lote ou rebanho parasitado sem se recorrer a exames de pâncreas.

Por fim, à semelhança do que fora estabelecido para outros helmintos ${ }^{34}$, nas Tab. 4 e 5 são apresentadas, respectivamentc, as diferenças possíveis de serem acusadas entre os graus de lesão, tomando-se o OPG médio dos animais pertencentes a cada um deles, e os intervalos de confiança para as médias de cada um dos graus de lesão. Como se deduz, a caracterização dos graus de lesão, tomando-se o OPG como parâmetro, é mais difícil do que a partir do número de parasitas,pois, além dela ser afetada pelos fatores que podem interferir na caracterização dos graus de lesão pela carga parasitária, inclucmse os outros capazes de interferir no OPG, já mencionados. Todavia, o interesse pelo OPG justifica-se, pelo fato de ser ele um instrumento disponível na prática da clínica, enquanto a carga parasitária só poderia ser empregada quando se realizasse exame "post-mortem".

A despeito de ter se conseguido, ainda que de forma não muito satisfatória, a separação dos quatro graus de lesão estabelccidos tomando-se o OPG como parâmetro, deve-se ter consciência de que se lesões mais extensas fossem encontradas e, portanto, outros graus de lesão considerados, talvez os resultados fossem mais desanimadores pois, em tais casos, onde normalmente predominam fibroses estensas 1,3.4.7.8.11.14,17. $19,21,22,27,33$, há uma tendência à localização dos helmintos em ductos de menor calibre ${ }^{1,33}$ e obstrução de outros ${ }^{8,10,11,12,20,31,33}$, o que pode determinar retenção dos ovos ${ }^{11,23.33}$ e prejudicar o escoamento deles para a luz intestinal, diminuindo, assim, o número de ovos nas fezes. Ademais, os parasitas parecem, indiretamente, sofrer o efeito das lesões pancreáticas, pois eles, nestes casos, apresentam-se em geral pálidos, atrofiados ou são de tamanho reduzido' e, em consequiência disso, podese esperar diminuição da ovipostura.

Diante do que acaba de ser dicutido, pode-se inferir que nem sempre o OPG vá se prestar para caracterizar graus de lesão, sobretudo nos casos mais avançados. Entretanto, são exatamente csses que dispensam a determinação do OPG, pois os sintomas da euritrematose, pricipalmente aqueles consequientes da insuficência pancreática endócrina ${ }^{3.8 .11 .14 .15}$, deverão se manifestar e isso, aliado ao simples achado de ovos de Eurytrema sp nas fezes, tornaria possível fechar o diagnóstico clínico da parasitose em questão.

\section{CONCLUSÕES}

$\left.1^{9}\right)$ As lesões pancreáticas, de acordo com suas características histológicas e extensão desde o epitélio dos ductos até o parênquima, em pelo menos $50 \%$ dos cortes histológicos examinados, podem ser enquadradas $\mathrm{em}$ quatro graus distintos:

GRAU I: lesões ausentes ou incipientes c geralmente restritas ao epitélio dos ductos;

GRAU II: casos que apresentem espessamento moderado, porém nítido, das paredes dos ductos associado à hiperplasia epitelial, infiltrado inflamatório e/ou fibroplasia discreta sem, contudo, ocorrer tendência à diminuição da luz;

GRAU III: alterações confinadas aos ductos interlobulares, principalmente de maior calibre, e traduzidas, sobretudo, por espessamento marcante das paredes devido à fibroplasia e reação inflamatória que, muitas vezes, ocasionam estenose;

GRAU IV: ocorrência de lesões ductais descritas para o grau III associadas a outras parenquimatosas de extensão variável, caracterizadas principalmentc por reação inflamatória e fibrose.

$\left.2^{\circ}\right)$ Sem se recorrer a exames histológicos de pâncreas, cm rebanhos onde a infecção em apreço tenha sido diagnosticada por meio de exames parasitológicos de fezes ou "post-mortem", é possível caracterizar satisfatoriamente o grau de lesão pancreática apresentado pelos bovinos infectados quando se tomam como parâmetros as 


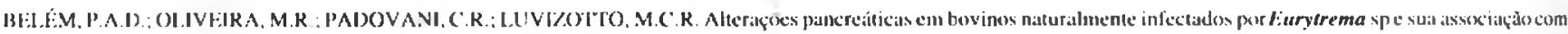

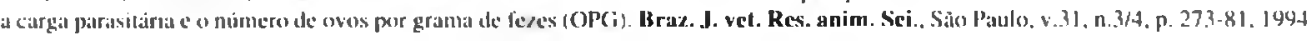

médias do OPG c/ou da carga parasitária.

3ํ) em vista das comparações entre os valores médios do OPG e do número de espécimes de Eurytrema por bovino, nos quatro graus de lesão encontrados, há uma melhor identificação destes quando se considera a carga parasitária.

$4^{\circ}$ ) as médias da carga parasitária (CP) e OPG (OPG), para os graus de lesão considerados, situam-se, respectivamente, dentro dos seguintes limites de confiança:

\begin{tabular}{ccccc}
\hline $\begin{array}{c}\text { GRALS } \\
\text { IJI } \\
\text { LESÃO }\end{array}$ & \multicolumn{2}{c}{ I.IMITES PARA CP } & \multicolumn{2}{c}{ LIMITES PARA OPG } \\
\cline { 2 - 5 } & INFERIOR & SUPERIOR & INFERIOR & SUPERIOR \\
\hline I & 13.16 & 94.84 & 0.00 & 3.81 \\
II & 96.99 & 263.21 & 2.86 & 20.25 \\
III & 252.00 & 525.27 & 6.78 & 24.36 \\
IV & 470.10 & 1025.87 & 15.58 & 54.86 \\
\hline
\end{tabular}

\section{TABELA 1}

Graus de lesão pancreática (I a IV) e respectivos valores das cargas parasitárias (CP) e dos OPG observados em 41 hovinos naturalmente infectados por Eurytrema sp e oriundos de municípios da mesorregião do Sudoeste Paulista no período compreendido entre 23/11/87 a 25/1/88.

\begin{tabular}{|c|c|c|c|c|c|c|c|}
\hline \multicolumn{2}{|c|}{1} & \multicolumn{2}{|c|}{ II } & \multicolumn{2}{|c|}{111} & \multicolumn{2}{|c|}{ IV } \\
\hline $\mathrm{CP}^{\mathrm{P}}$ & OPG & $\mathrm{CP}^{2}$ & OPG & $C P$ & OPG & $\mathrm{CP}$ & OPG \\
\hline 4 & 0 & 31 & - & 167 & 15 & 203 & 37 \\
\hline 34 & 1 & 42 & 19 & 177 & 8 & 204 & 80 \\
\hline 35 & 2 & 124 & 2 & 218 & 1 & 477 & 12 \\
\hline 44 & 0 & 132 & 5 & 228 & 15 & 578 & 12 \\
\hline 46 & 0 & 143 & 16 & 231 & 12 & 712 & 4 \\
\hline 72 & () & 148 & 11 & 315 & 6 & 759 & 66 \\
\hline \multirow[t]{8}{*}{14.3} & 7 & 210 & 7 & 342 & 16 & 94.3 & 40 \\
\hline & & 254 & 1 & 356 & 0 & 1159 & 24 \\
\hline & & 323 & 6 & 357 & 18 & 1165 & 42 \\
\hline & & 394 & 37 & 372 & 20 & 1280 & - \\
\hline & & & & 391 & 6 & & \\
\hline & & & & 580 & 21 & & \\
\hline & & & & 662 & 62 & & \\
\hline & & & & 1045 & 21 & & \\
\hline
\end{tabular}

\section{TABEI,A 2}

Cargas parasitárias médias segundo graus de lesão pancreática (1 a IV) verificados em bovinos naturalmente infectados por Eurytrema sp e oriundos de municípios da mesorregiăo do Sudoeste Paulista no período compreendido entre 23/11/ 87 e $25 / 1 / 88$.

\begin{tabular}{lllll}
\hline & I & II & III & IV \\
\hline & $6.80 * a * *$ & 12.71 a & $19.04 \mathrm{~b}$ & $26,3.3 \mathrm{c}$ \\
\hline $\mathrm{CV}=$ & $\begin{array}{l}32,53 \% \\
\text { dados sob a transformação rai\% quadrada da carga } \\
\text { parasitária } \\
\text { médias seguidas de uma mesma letra não diferem entre } \\
\text { si }\end{array}$
\end{tabular}

\section{TABELA 3}

Intervalos de confiança para as cargas parasitárias médias (dados não transformados), em cada grau de lesão pancreática (I a IV), verificados em ovinos naturalmente infectados por Furytrema sp e oriundos de municípios da mesorregião do Sudoeste Paulista no período compreendido entre 23/11/ 87 e $25 / 1 / 88$.

\begin{tabular}{|c|c|c|}
\hline \multirow{2}{*}{ GRAUS DE LESĀO } & \multicolumn{2}{|c|}{ LIMITY:S DE CONFIANCA } \\
\hline & Inferior & Superior \\
\hline I & 13.16 & 94.84 \\
\hline II & 96,99 & 263.21 \\
\hline III & 252.00 & 525.27 \\
\hline IV & 470,00 & 1025.87 \\
\hline
\end{tabular}

TABEI,A 4

Médias do OPG segundo graus de lesão pancrética (I a IV) verificados em 41 bovinos naturalmente infectados por Eurytrema sp e oriundos de municípios da mesorregião do Sudoeste Paulista no período compreendido entre 23/11/87 a $25 / 1 / 88$

\begin{tabular}{cccc}
\hline I & II & III & IV \\
\hline $1.20 * \mathrm{a} * *$ & $3.16 \mathrm{ab}$ & $3.6 .3 \mathrm{bc}$ & $5.59 \mathrm{c}$ \\
\hline
\end{tabular}

$\mathrm{CV}=48.74 \%$

* dados sob a transformação raiz quadrada do (OPG + 0,5)

** médias seguidas de uma mesma letra não diferem entre si 
BE:LÉM. P.A.D.; OI.IVI:IRA, M.R.; PADOVANI. C.R.; L.UVIZOTTO, M.C.R. Alıeraçües pancréticas em bovinos naturalmente infeclados por Eurtrema spe sua axsociaçăo com a carga parasilária e o número de ovos por grama de fezes (OPG). Braz. J. vet. Kes. anim. Sci.. Såo Paulo, v.31, n.3/4. p. 273-81. 1944

\section{TABELA 5}

Intervalos de confiança para o OPG médio (dados não transformados) em cada um dos graus de lesão pancreática (I a IV) verificados em bovinos naturalmente infectados por Eurytrema sp e oriundos de municípios da mesorregião do Sudocste Paulista no período compreendido entre 23/11/87 a $25 / 1 / 88$

\begin{tabular}{|c|c|c|}
\hline \multirow{2}{*}{ GRAUS DE LESÃO } & \multicolumn{2}{|c|}{ LIMITES DE CONFIANÇA } \\
\hline & Inferior & Superior \\
\hline I & $0^{*}$ & 3,81 \\
\hline II & 2.86 & 20,25 \\
\hline III & 6,78 & 24,36 \\
\hline IV & 15,58 & 54,86 \\
\hline
\end{tabular}

* este representa o valor biológico, mas o limite real encontrado correspondeu a - 0,93 OPG

\section{SUMMARY}

Microscopic lesions in pancreas of Eurytrema sp naturally infected caltle $(n=41)$ were classified into four different gradations, according to the extension of the lesions on the mucosa of pancreatic ducts. Then, by taking the parasite load and number of eggs per gram of faeces (EPG) of each animal, the lesion gradations found were satisfactorily infered, but is was showed that the first parameter is a better measure to estimate lesion extension than the EPG.

UNITERMS: Eurytrema; pancreas; lesions; parasites

\section{REFERÊNCIAS BIBLIOGRÁFICAS}

01-BASCH, P.F. Completion of the life cycle of Eurytrema pancreaticum (Trematoda: Dicrocoeliidac). Journal of Parasitology. v.51, p.350-5, 1965.

02-BELEM , P.A.D.; OLIVEIRA. M.R.; PADOVANI, C.R. Adaptação da técnica de Dennis, Stone \& Swanson para diagnóstico copro-parasitológico de infecção por Eurytrema sp em bovinos. Brazilian Journal of Veterinary Research and Animal Science, v.29, n.2. p.303-7, 1992.

03-BELEM, P.A.D.; SILVA.J.C.P.: VIEIRA. D. Diabete mellitus em bovino. In: ENCONTRO DE PESQUISAS VETERINARIAS, 11 ., Jaboticabal, 1986. Resumos. Jaboticabal, Faculdade de Ciências Agrárias e Veterinárias, 1986. p.62.

04-BORAY, J.C. Flukes of domestic animals. In: GAAFAR, S.M.; HOWARD, W.E.; NARSH, R.E. eds. Parasites pests and predators. Amsterdam, Elsevier, 1985. p.179-218.

05-BRITO, B.D.; FRANCIS, M.; CARVALHO, E.C.Q.; MIRANDA, Z.B.; ALMEIDA, W.M. Patogenicidade do Eurytrema coelomaticum (Giard \& Billet, 1892; Loos, 1907). Revista Brasileira de Veterinária, v.4, n.4, p.17. 1981./ Apresentado ao 4. Congresso
Fluminense de Medicina Veterinária, Rio de Janeiro, 1981 - Resumo.

06-BURGGRAAF, H. Bijdrage tot de Kennis der Pancreasdistomatose bij het rund, veroorzaakt door Eurytrema pancreaticum (Janson, 1889; Loos, 1907). Tijdschrift voor Diergeneeskunde. v.60. p. 1277-82. 1933.

07-BURGGRAAF, H. Ern geval van tumorvorming bij pancreasdistomatose van het rund. Geneeskunding Tijdschrift voor Nederlandsch Indie, v.75, p. 1399406, 1935.

08-BURGGRAAF, H. Pâncreas-distomatose. Tijdschrift Diergeneeskunde, v.62, p.399-407, 479-81, 1935.

09-CAMPOS, M.S.: RAGUSA, A.L.; MIGUEL, O.; ISHIZUKA, M.M. Correlação entre número de parasitas e peso de pâncreas em bovinos naturalmente infestados porEurytrema pancreaticum, Janson, 1889 (Trematoda: Dicrocoeliidae); diferença de peso entre pâncreas parasitados e não parasitados. Revista da Faculdade de Medicina Veterinária e Zootecnia da Universidade de São Paulo, v.11, p.295-9, 1974. 
BELLF, P.A.D.; OLIVEIRA. M.R.: PADOVANI. C.R.: L.UVIZOTTO. M.C.R. Alteraçöes pancreáticas em bovinos naturalmente infectados por Eurytrema spe sua asioxią̧ăo com u carga parasitúria e o número de ovos por grama de fezes (OPG). Braz. J. vet. Res. anim. Sci., Săo Paulo, v.31, n.3/4, p. 273-81. 1994

10-CORREA, W.M.; CORREA, C.N.M.; FERREIRA, A.C.; PAES, A.C. Eurytrema pancreaticum: clínica e diagnóstico em bovinos. Hora Veterinaria, v.4, n.19, p. $31-4,1984$.

11-FIGUEIREDO, C.B. Sobre as lesões do pâncreas de boi produzidas pelo Eurytrema pancreaticum. Memórias do Instituto Oswaldo Cruz, v.3, p.1-4, 1928. Suplemento.

12-FREITAS, M.G. Helmintologia veterinária. Belo Horizonte, Rabelo \& Brasil, 1976.

13-GETTY, R. Anatomia dos animais domésticos. 5.ed. Rio de Janeiro, Guanabara Koogan, 1986.

14-HARADA, H.; WATO, N.; FUJIWARA, N.; NISHIRO, N.; OKUDA, H. Eurytrema infection in dairy cattle. Journal Veterinary Medicine. v. 707, p. 328-31, 1980.

15-HORTA, P.P. Distomatose pancreática c glicosúria cm bovinos. A Lavoura, v.22, n.3/4, p.157-8, 1918.

16-JONES. T.C.; HUNT, R.D. Veterinary pathology. 5.ed. Philadelphia, Lea \& Febiger, 1983.

17-JUBB, K.V.F.; KENNEDY,P.C.; PALMER, N.Pathology of domestic animals. 3.ed. New York, Academic Press, 1985. 3v.

18-KONO, I.; FUKUYOSHI, S. Studies on the existence of eggs of pancreas fluke in the wall of the pancreatic duct and its significance. Bulletin of the Faculty of Agriculture, Kagoshima University, v.30, p. I1 I-6, 1980.

19-KONO, I,; SAKAMOTO, T.; YASUDA, N.; KITANO, Y.; TOGOE, T.; YAMAMOTO,Y.Pathological studies on the cattle heavily infected with Eurytrema coelomaticum. Bulletin of the Faculty of Agriculture, Kagoshima University, v.30, p.111-6, 1980.

20-MARTIN, O.C. The incidence of Eurytrema pancreaticum (Loos, 1907) in dairy cattle at the DTRI farm. Phillipp. Agric., v.56, n.1/2, p.25-34, 1972.

2 I-NIEBERLE, K.; COHRS, P. Anatomia patológica especial dos animais domésticos. Lisboa, Fundação Calouste Gulbenkian, 1970. v.1.

22-NOSAKA, D.; ASHIZAWA, H.; NAGATA, Y. Pathological studies on bovine eurytremiasis. II. Histological findings in the bovine pancreas infected with Eurytrema species. Bulletin of the Faculty of Agriculture, University of Miyazaki, v.16, p.174201,1969

23-NOSAKA, D.; ASHIZAWA, H.; NAGATA, Y. Pathological studies on bovine eurytremiasis. IlI. Behaviour of Eurytrema eggs in the wall and surrounding tissue of the bovine ducts infected with Eurytrema species. Bulletin of the Faculty of Agriculture, University of Miyazaki, v.17, p.10432,1970 .

24-OLIVEIRA, G.P.; BECHARA, G.H. Aspectos microscópicos do pâncreas de bovino parasitado porEurytrema coelomaticum. Giard \& Billet, 1892 (Trematoda: Dicrocoeliidac). Arquivos de Biologia e Tecnologia, v.31, n.2, p.275-9. 1988.

25-OSTLE, B. Estadistica aplicada. 3.ed., Mexico, LimusaWiley, 1973.

26-PURVIS, G.B. On the apparent non pathogenicity of the trematodes Eurytrema pancreaticum (Janson, 1889) and Platynosomum concinum (Braun, 1901). Veterinary Record. v.13, n.42, p.1063-4, 1933

27-RIBEIRO, O.C.; BIANCHIN, I.; MELO, H.J.H.; GOMES, A.; PEREIRA, A.S. Lesôes anátomo-patológicas observadas em infecções por Eurytrema pancreaticum em bovinos. In: CONGRESSO BRASILEIRO DE MEDICINA VETERINARIA, 17., Fortaleza, 1980. Anais. Fortaleza, 1980. p.174.

28-SAKAMOTO. T.; KONO, I.; MOHRI, S. Studies on Eurytrema coelomaticum. IV. Comparision between anthelmintic effects of drugs against Eurytrema coelomaticum "in vitro" and "in vivo".Journal of the Faculty of Agriculture, Iwate University, v.17, p.211$27,1984$.

29-SAKAMOTO, T.; KONO, I.; YASUDA, N.; YAMAMOTO, Y.; NAKAGAWA, H. Studies on Eurytrema coelomaticum. 11. The anthelmintic efficicncy of nitroxynil and praziquntel against Eurytrema coelomaticum in cattle. Memoirs of Faculty of Agriculture, Kagoshima University, v, I6, p.93-101, 1980.

30-SAKAMOTO, H.; TASHIRO, T.: WATANABE, S.; SAKAMOTO, T.; KONO, I.; YASUDA, N. Clinicopathological findings of cattle infected with Eurytrema coelomaticum. Bulletin of the Faculty of Agriculture, Kagoshima University, v.30, p.117$20,1980$.

31 -SEIFRIED, O. Curso de histopatologia, 1936 apud CODO, V. Teste cutâneo para diagnóstico da curitrematose em bovinos. Revista Ceres, v.9, n.50, p.132-8, 1952.

32-SHIEN, Y.S.; YANG. P.C.; LIU, J.J.; HUANG, S.W. Studies on eurytremiasis. (2) Pathological study of pancreas of cattle and goats naturally infected with Eurytrema pancreaticum. Journal of the Chinese Society Veterinary Science, v.5, p.133-8, 1979. 
33-TORRES, C.M.; PINTO, C. Processos patogênicos determinados pelos trematóides Eurytrema fastosum e Eurytrema coelomaticum (Dicrocoeliidae). Memórias do Instituto Oswaldo Cruz, v.31, n.4, p.731-46, 1936.

34-UENO, H.; GONÇALVES, P.C. Manual para diagnóstico das helmintoses de ruminantes. 2.ed. Toquio, International Cooperation Agency, 1988.
35-WHITLOCK, R.H.; DEEM, D.A. Pancreatitis: pancreatic parasites. In: HOWARD, J.L. Current veterinary therapy; food animal practice. Philadelphia, W.-B. Saunders, 1981. p.918.

Recebido para publicação em 26/03/93 Aprovado para publicação em 03/03/94 